\title{
LES DIMENSIONS COMMUNICATIONNELLES DU RECRUTEMENT
} Daniel Pélissier

C.N.R.S. Editions | «Hermès, La Revue »

2018/3 n 82 | pages 154 à 159

ISSN 0767-9513

ISBN 9782271122582

Article disponible en ligne à l'adresse :

https://www.cairn.info/revue-hermes-la-revue-2018-3-page-154.htm

Distribution électronique Cairn.info pour C.N.R.S. Editions.

(c) C.N.R.S. Editions. Tous droits réservés pour tous pays.

La reproduction ou représentation de cet article, notamment par photocopie, n'est autorisée que dans les limites des conditions générales d'utilisation du site ou, le cas échéant, des conditions générales de la licence souscrite par votre établissement. Toute autre reproduction ou représentation, en tout ou partie, sous quelque forme et de quelque manière que ce soit, est interdite sauf accord préalable et écrit de l'éditeur, en dehors des cas prévus par la législation en vigueur en France. Il est précisé que son stockage dans une base de données est également interdit. 


\section{Daniel Pélissier}

Université Toulouse 1 Capitole - IUT de Rodez

\section{Les dimensions communicationnelles du recrutement}

\section{Le recrutement d'Hermès}

Plus qu'un voyageur, Hermès fut un explorateur qui a même visité son infernal oncle, Hadès. Ce dernier lui proposa une mission : accompagner les ombres dans leur lugubre parcours. Cette offre qui commença par une rencontre, un rapprochement familial et stratégique entre les Enfers et l'Olympe, est ce qui est nommé actuellement un recrutement. Hermès fut ainsi recruté par Hadès sans CV ni lettre de motivation, sans entretien particulier, sans avoir consulté longuement le site internet des Enfers, sans avoir créé non plus de profil sur Linkedin... Ce récit mythologique renvoie à la nature même du recrutement, une mise en relation entre un candidat potentiel et une organisation.

Cette métaphore souligne aussi quelques évolutions de ce contact particulier entre individu et organisation. D'autres sont apparues avec la numérisation farouche de la relation, comme l'usage de la réalité virtuelle, la création de jeux sérieux, etc.

Le regard du chercheur sur cette situation protéiforme peut porter sur l'efficacité des étapes du processus, sur la performance de l'attractivité de l'organisation, sur l'adéquation des compétences du candidat, sur les relations de domination entre candidat et organisation, sur les risques de discrimination, etc.

Nous approcherons le recrutement comme un phénomène communicationnel construisant une relation entre un candidat et une organisation et fondé sur l'altérité.

Ce postulat aux accents d'évidence est cependant masqué par des discours prométhéens qui transforment le recrutement en fer de lance des avancées technologiques ou en porte-drapeau de la marketisation du monde. Étudier le recrutement comme phénomène communicationnel exige ainsi un rigoureux exercice de pensée pour montrer toute la complexité d'une construction au-delà des discours simplificateurs. Se pose alors la question épistémologique et méthodologique de savoir comment approcher scientifiquement cette voie de recherche.

Dans cet article, nous argumenterons notre posture scientifique dans la perspective d'un recrutement communicationnel et nous l'illustrerons par le parcours de deux axes : le premier est centré sur une approche médiatique du recrutement, la deuxième est en construction et s'intéresse à l'intégration d'une intelligence artificielle dans ce processus. Nous ouvrirons enfin cette réflexion en soulignant ses enjeux sans oublier la divinité tutélaire, Hermès. 